\title{
Knowledge, attitudes and beliefs towards e-cigarettes among e-cigarette users and stop smoking advisors in South East England: a qualitative study
}

\section{Nancy Tamimi}

Department of Social Sciences, Media \& Communications, Brunel University London, Uxbridge UB8 3PH, United Kingdom

\begin{abstract}
Aim: To explore how e-cigarettes are perceived by a group of e-cigarette users and a group of Stop Smoking Advisors (SSAs), what are the risks and benefits they associate with e-cigarettes and how do these understandings shape participants' attitude towards e-cigarettes? Method: Face-to-face and phone interviews were conducted with 15 e-cigarette users and 13 SSAs in South East England between 2014 and 2015. Transcribed data were analysed inductively through thematic analysis. Findings: E-cigarettes were used as a therapeutic aid to stop or cut down smoking and as a smoking substitute. A prominent theme is the uncertainty e-cigarettes have generated. This included ambiguity of e-cigarettes' status and efficacy, and ambiguity of e-cigarettes' physical and social risks. Different attitudes towards e-cigarettes were identified. Conclusion: E-cigarettes' benefits and risks should be continuously evaluated, put into perspective and circulated to avoid ambiguity. Stop smoking services need to recognise the benefits that can be gained by using e-cigarettes as a harm reduction tool.
\end{abstract}

Key words: e-cigarettes; qualitative research; smoking

Received 22 November 2016; revised 17 June 2017; accepted 26 June 2017; first published online 4 August 2017

\section{Background}

In Britain, it was estimated that in 2016, 2.8 million adults used e-cigarettes; mainly current and exsmokers (ASH, 2016a). The top reasons for using e-cigarettes are to help stop smoking and reduce harm (McNeill et al., 2015). Some evidence shows that e-cigarettes can help smokers to quit smoking and reduce cigarette consumption (McRobbie et al., 2014; McNeill et al., 2015). Although existing research does not provide a definitive conclusion about their safety in absolute terms, there is an indication that they are less harmful than tobacco cigarettes and comparable in toxicity to approved Nicotine Replacement Therapies (NRTs) (NCSCT, 2016). However, their position within tobacco control is still controversial

Correspondence to: Nancy Tamimi. Emails: nancy.tamimi @brunel.ac.uk; nancy_altamimi@hotmail.com
(RCP, 2016). Many consider e-cigarettes a breakthrough in public health and harm reduction history (Hajek et al., 2014; McNeill et al., 2015). Others warn that their safety, quality and long-term use have not been established fully and therefore oppose their promotion (Chapman, 2014).

Stop Smoking Services (SSSs) in England train stop smoking advisors (SSAs) to support smokers who want to quit through providing accessible, evidence-based and cost-effective services (DOH, 2011). Their current practice includes offering treatments such as NRTs aiming at stopping smoking with the view of ending nicotine use (NICE, 2008). Some evidence indicates that NRTs are an effective intervention (Kamerow, 2012), other questions their effectiveness (Alpert et al., 2013).

Tobacco harm reduction approach implies that 'it is safer to use licensed nicotine-containing products than to smoke' and that their 'lifetime use [...] will be considerably less harmful than 
smoking' (NICE, 2013: 10). However, many smokers find NRTs unsatisfactory as long-term substitutes for smoking (RCP, 2016: 7). In contrast, e-cigarettes have the potential to permanently replace cigarettes (Bell and Keane, 2012) because they imitate features of smoking and this is making them a popular and effective substitute to smoking (RCP, 2016: 70). However, some mainstream tobacco control opinions consider e-cigarettes a threat to their efforts to denormalise smoking through eliminating the visibility of the smoking behaviour (Bell and Keane, 2012; De et al., 2013). Concerns were raised that e-cigarettes might glamorise smoking, provide an entryway for people to become addicted or deter smokers from using existing cessation aids (De and Hastings, 2013).

This study was part of a self-funded Doctoral degree in Social Sciences. Ethical approvals were gained from the Social Care NREC, Public Health Directorate in two counties in South East (SE) England and the University Ethical Committee. At the time, SSSs were not prescribing or recommending e-cigarettes but were seeing an increase in service users asking about and using e-cigarettes. SSAs were advised to tell people that these products are not regulated and 'therefore, their effectiveness, safety and quality cannot be assured', but to advise 'that these products are likely to be less harmful than cigarettes' (NICE, 2013: 15).

Other studies highlighted the concerns and perceptions that health practitioners hold for e-cigarettes at UK SSSs (Beard et al., 2014; Hiscock et al., 2014). This study explores the knowledge, attitudes and beliefs towards e-cigarettes (without particular focus on smoking cessation) among a group of e-cigarette users and a group of SSAs in SE England. It aims to answer three questions: (1) how are e-cigarettes perceived by the e-cigarette users and SSAs? (2) what are the risks and benefits associated with e-cigarettes, as perceived by both groups? (3) how do these understandings shape participants' attitude towards e-cigarettes?

\section{Method}

The study was conducted between 2014 and 2015 and used a convenience sampling. SSAs were invited to participate in the research and invite their clients who use e-cigarettes to participate. Leaflets and posters were distributed at some local shops and e-cigarette stores and an advert was put on some social media platforms and on the University website; inviting e-cigarette users to participate. Face to face and phone semi-structured interviews were used. Based on the literature review, a draft interview topic guide was designed to explore reasons of and attitudes towards e-cigarette use; perceptions of their status, efficacy, risk and/or benefit. Phone interviews were offered to participants if found more convenient to them than face to face interview. The sample consisted of 13 SSAs from two SSSs in two counties in SE England (seven from one county and six from the other; nine females and four males) and 15 current e-cigarette users (median age 44 years (range $21-67) ; 60 \%(n=9)$ males; $33 \%(n=5)$ were SSSs users; duration of e-cigarette use ranged between 4 and 36 months (average 14.6 months); 53\% $(n=8)$ were ex-smokers (the rest still smoked either occasionally or regularly). Appendix 1 shows relevant demographic characteristics of e-cigarette users. An inductive approach of thematic analysis was used using QSR NVivo10 and applying the six phases framework proposed by Braun and Clarke (2006). Appendix 2 shows the process of coding.

\section{Findings}

Two main themes were identified from the analysis.

\section{Theme 1: the reasons for using e-cigarettes}

E-cigarettes were used as a therapeutic aid to stop or cut down smoking and as a smoking substitute. Their efficacy was attributed to: replicating the habitual and rituals of smoking; offering comfort and pleasure; delivering nicotine effectively; relieving withdrawal symptoms and helping in avoiding relapse to smoking. Both groups mentioned e-cigarettes' innovative modernistic features; flavours; reduced cost compared with cigarettes; tobacco-free smell; social acceptability and the possibility of customising them according to individual's needs and desires. Some users used e-cigarettes as a hobby and a social activity. Nearly all e-cigarette users opted to use e-cigarettes to improve their health. Two users mentioned they used them to save money without referring to 
health concerns. Some users reported being encouraged to use e-cigarettes instead of smoking by friends, family or health personnel.

\section{Theme 2: the ambiguity of e-cigarettes}

Both groups were heterogeneous in their attitudes, values and beliefs. The diverse perceptions that e-cigarettes have generated and the uncertainty associated with them were evident and can be classified into three subthemes:

(i) The ambiguity of e-cigarettes' status and efficacy. E-cigarettes were perceived and used as therapeutic products, recreational products, a smoking substitute and an addition for NRTs.

'I would rather view it as a medicine; as an aid to giving up smoking'.

$$
\text { (H1, advisor) }
$$

'For me it's a treatment. It's a way to keep me off tobacco'.

(14N, user)

'It is not a medicine and is certainly not a treatment'.

$$
\text { (2B, user) }
$$

Nearly all users and most of the advisors perceived e-cigarettes to be as effective as or more effective than NRTs. Their effectiveness in helping particular types of smokers to quit or reduce smoking was highlighted.

'I don't know, I am not certain. I think for people who are very addicted to the nicotine and very addicted to the habits surrounding the smoking, it could be the e-cigarette is the thing that help them to stop or at least the thing to taking nicotine at a relatively safe level without all the chemicals from tobacco and all the harm from Carbon monoxide.'

$$
\text { (H5, advisor) }
$$

(ii) The ambiguity of e-cigarettes' physical risks. E-cigarettes were perceived as safe products; safer alternative to smoking; an innovation with potential long-term threats; 'dangerous' and risky objects.
'I wish I could tell them with absolute surety what the safety is and I can't. I wish I can tell them with absolute surety how much nicotine they are getting from the product and I can't'.

(H6, advisor)

'My sense is that there's a lot of risk aversion around it because nobody can say it's safe, therefore it must be dangerous'.

(11K, user)

Some users described the health benefits of using e-cigarettes, like improving their lung function. All participants believed e-cigarettes to be less harmful than smoking. However, the advisors expressed more concerns than users, especially of the long-term effect.

(iii) The ambiguity of e-cigarettes' social risks. E-cigarettes were perceived as devices that might create addiction, maintain nicotine addiction, a gateway to smoking, a gateway from smoking, a smoking renormalisation threat and an approved habit with a possibility of developing stigma.

'The danger [it] may open up a door for an addiction they did not have to begin with...it's a double-edge sword'.

(H1, advisor)

'I think the stigma that smokers had has kind of carried on to the e-cigarette users in the sense that the stigma surrounding the addiction itself. People see you as weak because you give in to the addiction because you obviously don't have willpower enough to stop, so it's kind of the moral judgement...'

(12L, user).

In the face of e-cigarettes' ambiguity and potential risks, nearly all the advisors favoured a medicinal regulation for e-cigarettes to ensure safety and to add them to their prescription list, aiming at eliminating nicotine use. They disapproved e-cigarettes' resemblance to conventional cigarettes and favoured their ban in public places to avoid any potential risk. Conversely, nearly all e-cigarette users disapproved e-cigarettes' 
ban in public places. The users placed e-cigarettes in a smoking quitting continuum where boundaries are blurry and where they can tailor their use according to their lifestyle, needs and desires.

\section{Discussion and conclusion}

Similar to other qualitative studies, this study is subject to criticisms (Diefenbach, 2009; Bryman, 2012). The lack of generalisability of findings could be construed as a weakness. However, this was purposely a small qualitative study and was not designed to fulfil the generalisability requirement, rather it focused on garnering individual accounts of e-cigarette perceptions. A potential limitation is using two different interview methods; however, there was a high degree of thematic commonality provided via both approaches. To address validity, interviews were recorded and transcribed. Participants' direct quotes were used and themes were continuously revised and verified with two $\mathrm{PhD}$ supervisors.

The findings on the reasons of e-cigarette use conform to results from other studies (Dawkins et al., 2013; Dockrell et al., 2013; ASH, 2016b). Although other studies found that some e-cigarette users reported stopping using e-cigarettes based on advice they had received from a health professional (ASH, 2016b), in this study, some users reported health personnel's approval to use e-cigarettes instead of smoking. Similar to other studies, e-cigarettes' relative safety compared with traditional cigarettes was emphasised (Dawkins et al., 2013; Pepper and Brewer, 2014; Pepper et al., 2015; Baweja et al., 2016). Although participants in one study viewed e-cigarettes differently to NRTs (Rooke et al., 2016), e-cigarettes, in this study, were perceived to be as effective as or more than NRTs.

The findings have provided new insights into SSAs' attitudes towards e-cigarettes. SSAs envisaged e-cigarettes' potential benefits to some cohorts. However, their aim at stopping nicotine use does not reflect harm reduction approaches in nicotine addiction which aim at minimising the effect of consuming nicotine rather than eliminating its use, as recommended by leading health organisations (NICE, 2013).

Both groups demonstrated uncertainty with regards to the status, efficacy and risks associated with e-cigarettes. Some of these concerns lack empirical evidence such as the gateway and smoking renormalisation concerns (NCSCT, 2016). Similar uncertainty, concerns and disagreement were found in other studies (Pepper and Brewer, 2014; Beard et al., 2014; Hiscock et al., 2014; Rooke et al., 2016; Sherratt et al., 2015, 2016). These expressed demonstrations of uncertainty may possibly reflect the circulated controversy in the media. Ambiguity and fear played a major part in stigmatising other biotechnological innovations, health conditions and behaviours (Gregory et al., 1996; Stuber et al., 2008). Stigma has multiple forms and severities including negative stereotyping and experiences of discrimination (Stuber et al., 2009). If ambiguity of e-cigarettes persisted, some forms of stigma might develop.

To avoid stigma and amplification of risk, public health messages should address the uncertainty and different perceptions of e-cigarettes and highlight the difference between stop the use of nicotine and stop smoking. E-cigarettes' benefits and risks should be continuously evaluated, put into perspective in comparison with harms inflicted by tobacco use, and circulated among media channels and health services to minimise ambiguity and non-evidencebased concerns. Stop smoking services need to recognise the potential benefits gained by using e-cigarettes as a harm reduction tool and focus on stopping smoking rather than stopping nicotine. Indeed, the latest guidelines by The National Centre for Smoking Cessation and Training have incorporated similar recommendations to SSAs (NCSCT, 2016). Further research could reveal the changes of attitudes towards e-cigarettes among SSAs following these new recommendations.

\section{Acknowledgements}

I am grateful to all of the study participants and the various gatekeepers. I thank my supervisors for supporting my PhD work, especially Dr Hauke Riesch for reading this article before sending to the journal.

\section{Financial Support}

Self-funded.

\section{Conflicts of Interest}

None. 


\section{References}

Action on Smoking and Health (ASH) 2016a: Use of electronic cigarettes (vapourisers) among adults in Great Britain. Fact sheet. Retrieved 25 May 2016 from http://www.ash.org.uk/ files/documents/ASH_891.pdf.

Action on Smoking and Health (ASH) 2016b: Electronic cigarettes (also known as vapourisers). Retrieved 20 May 2016 from http://ash.org.uk/files/documents/ASH_715.pdf.

Alpert, H.R., Connolly, G.N. and Biener, L.A. 2013: prospective cohort study challenging the effectiveness of population-based medical intervention for smoking cessation. Tobacco Control 22, 32-37.

Baweja, R., Curci, K.M., Yingst, J., Veldheer, S., Hrabovsky, S., Wilson, S.J., Nichols, T.T., Eissenberg, T. and Foulds, J. 2016: Views of experienced electronic cigarette users. Addiction Research and Theory 24, 80-88.

Beard, E., Brose, L.S., Brown, J., West, R. and McEwen, A. 2014: How are the English stop smoking services responding to growth in use of electronic cigarettes? Patient Education Counseling 94, 276-81.

Bell, K. and Keane, H. 2012: Nicotine control: E-cigarettes, smoking and addiction. International Journal of Drug Policy 23, 242-47.

Braun, V. and Clarke, V. 2006: Using thematic analysis in psychology. Qualitative Research in Psychology 3, 77-101.

Bryman, A. 2012. Social research methods, fourth edition. Oxford: Oxford University Press.

Chapman, S. 2014: E-cigarettes: the best and the worst case scenarios for public health - an essay by Simon Chapman. British Medical Journal 349, g5512-g5514.

Dawkins, L., Turner, J., Roberts, A. and Soar, K. 2013: 'Vaping' profiles and preferences: an online survey of electronic cigarette users. Addiction 108, 1115-125.

de Andrade, M. and Hastings, G. 2013: Research priorities and policy directions. Tobacco harm reduction and nicotine containing products, Cancer Research UK. Retrieved 17 Decemeber 2013 from http:/www.cancerresearchuk.org/ prod_consump/groups/cr_common/@nre/@pol/documents/ generalcontent/tobacco-harm-reduction.pdf.

de Andrade, M., Hastings, G. and Angus, K. 2013: Promotion of electronic cigarettes: tobacco marketing reinvented. British Medical Journal 347, f7473.

Department of Health (DOH) 2011. Healthy lives, healthy people: a tobacco control plan for England. London: Her Majesty's Stationery Office.

Diefenbach, T. 2009: Are case studies more than sophisticated storytelling?: methodological problems of qualitative empirical research mainly based on semi-structured interviews. Quality and Quantity 43, 875-94.

Dockrell, M., Morrison, R., Bauld, L. and McNeill, A. 2013: E-cigarettes: prevalence and attitudes in Great Britain. Nicotine Tobacco Research 15, 1737-744.

Gregory, R., Slovic, P. and Flynn, J. 1996: Risk perceptions, stigma, and health policy. Health Place 2, 213-20.

Hajek, P., Etter, J.F., Benowitz, N., Eissenberg, T. and McRobbie, H. 2014: Electronic cigarettes: review of use, content, safety, effects on smokers and potential for harm and benefit. Addiction 109, 1801-10.

Hiscock, R., Goniewicz, M.L., McEwen, A., Murray, S., Arnott, D., Dockrell, M. and Bauld, L. 2014: E-cigarettes: online survey of UK smoking cessation practitioners. Tobacco Induced Diseases 12, 1.

Kamerow, D. 2012: Does nicotine replacement really help smokers quit? British Medical Journal 344, 33.

McNeill, A., Brose, L.S., Calder, R., Hitchman, S.C., Hajek, P. and McRobbie, H. 2015. E-cigarettes: an evidence update. London: Public Health England.

McRobbie, H., Bullen, C., Hartmann-Boyce, J. and Hajek, P. 2014: Electronic cigarettes for smoking cessation and reduction. Cochrane Database Systematic Review 12, 18-20.

National Centre for Smoking Cessation and Training (NCSCT) 2016: Electronic cigarettes: a briefing for stop smoking services. Retrieved 15 April 2016 from http://www.ncsct. co.uk/usr/pub/Electronic_cigarettes._A_briefing_for_stop_ smoking_services.pdf.

National Institute for Health and Clinical Excellence (NICE) 2008: Stop smoking services. Retrieved 20 May 2014 from https://www.nice.org.uk/guidance/ph10/resources/stopsmoking-services-1996169822917.

National Institute for Health and Clinical Excellence (NICE) 2013: Smoking: harm reduction. Report. Retrieved 1 September 2013 https://www.nice.org.uk/guidance/ph45.

Pepper, J. K. and Brewer, N.T. 2014: Electronic nicotine delivery system (electronic cigarette) awareness, use, reactions and beliefs: a systematic review. Tobacco Control 23, 375-84.

Pepper, J.K., Emery, S.L., Ribisl, K.M., Rini, C.M. and Brewer, N.T. 2015: How risky is it to use e-cigarettes? Smokers' beliefs about their health risks from using novel and traditional tobacco products. Journal of Behavioral Medicine 38, 318-26.

Rooke, C., Cunningham-Burley, S. and Amos, A. 2016: Smokers' and ex-smokers' understanding of electronic cigarettes: a qualitative study. Tobacco Control 25, e60-e66.

Royal College of Physicians (RCP) 2016: Nicotine without smoke: Tobacco harm reduction. Nicotine without smoke. Tobacco harm reduction. A report by the Tobacco Advisory Group of the Royal College of Physicians. Retrieved 25 May 2016 from https:/www.rcplondon.ac.uk/projects/outputs/ nicotine-without-smoke-tobacco-harm-reduction-0.

Sherratt, F.C., Marcus, M.W., Robinson, J., Newson, L. and Field, J.K. 2015: Electronic cigarette use and risk perception in a Stop Smoking Service in England. Addiction Research and Theory 23, 336-42.

Sherratt, F.C., Newson, L., Marcus, M.W., Field, J.K. and Robinson, J. 2016: Perceptions towards electronic cigarettes for smoking cessation among Stop Smoking Service users. British Journal of Health Psychology 21, 421-433.

Stuber, J., Galea, S. and Link, B.G. 2008: Smoking and the emergence of a stigmatized social status. Social Science \& Medicine 67, 420-30.

Stuber, J., Galea, S. and Link, B. G. 2009: Stigma and smoking: the consequences of our good intentions. Social Service Review 83, 585-609. 


\section{Nancy Tamimi}

\section{Appendix}

Table A1 The demographic characteristics of e-cigarette users

\begin{tabular}{|c|c|c|c|c|c|c|c|c|}
\hline $\begin{array}{l}\text { E- } \\
\text { cigarette } \\
\text { users }\end{array}$ & Gender & Age & Occupation & $\begin{array}{l}\text { Stop } \\
\text { Smoking } \\
\text { Service } \\
\text { user }\end{array}$ & $\begin{array}{l}\text { Age } \\
\text { started } \\
\text { smoking } \\
\text { (year) }\end{array}$ & $\begin{array}{l}\text { Gave up } \\
\text { smoking } \\
\text { completely (at } \\
\text { the time of the } \\
\text { interview) }\end{array}$ & $\begin{array}{l}\text { Commenced } \\
\text { e-cigarettes use } \\
\text { (calculated until the } \\
\text { time of the } \\
\text { interview) }\end{array}$ & $\begin{array}{l}\text { Used other aids } \\
\text { to stop smoking: } \\
\text { NRT/Chapmix/ } \\
\text { herbal Allen } \\
\text { Carr/ hypnosis }\end{array}$ \\
\hline $1 \mathrm{~A}$ & Female & 44 & Counsellor & No & 15 & Yes & 8 months & No \\
\hline 2B & Male & 39 & $\begin{array}{l}\text { Audit } \\
\text { manager }\end{array}$ & $\begin{array}{l}\text { No/ex- } \\
\text { user }\end{array}$ & 12 & No & 2 years & Yes \\
\hline $3 C$ & Male & 36 & $\begin{array}{l}\text { Unemployed/ } \\
\text { disabled }\end{array}$ & $\begin{array}{l}\text { No/ex- } \\
\text { user }\end{array}$ & 14 & Yes & 3 years & Yes \\
\hline 4D & Female & 50 & $\begin{array}{l}\text { Unemployed/ } \\
\text { disabled }\end{array}$ & Yes & 20 & No & 6 months & Yes/ongoing \\
\hline $5 E$ & Female & 67 & Retired & Yes & $20 s$ & Yes & Few months & Yes/ongoing \\
\hline $6 \mathrm{~F}$ & Male & 44 & Unemployed & Yes & 9 & Yes & 3-4 months & Yes \\
\hline $7 G$ & Female & 31 & Unemployed & Yes & 19 & No & 15 months & Yes/ongoing \\
\hline $8 \mathrm{H}$ & Male & 51 & Surgeon & No & 22 & No & 4 months & Yes \\
\hline 9l & Male & 21 & IT worker & No & 16 & Yes & 2 years & Yes \\
\hline $10 \mathrm{~J}$ & Female & 37 & $\begin{array}{l}\text { Gym } \\
\text { instructor }\end{array}$ & No & 21 & Yes & 2 years & Yes \\
\hline $11 \mathrm{~K}$ & Male & 34 & Lecturer & No & 23 & Yes & $12-15$ months & Yes \\
\hline $12 \mathrm{~L}$ & Male & 38 & Lecturer & No & 18 & Yes & 2 years & Yes \\
\hline $13 \mathrm{M}$ & Male & 58 & Retired & No & 15 & No & 9 months & No \\
\hline $14 N$ & Male & 56 & $\begin{array}{l}\text { Artist/ } \\
\text { musician }\end{array}$ & Yes & 16 & No & 2 years & Yes \\
\hline 150 & Female & 60 & $\begin{array}{l}\text { Para legal in } \\
\text { family work }\end{array}$ & No & 15 & No & 7 months & Yes \\
\hline
\end{tabular}


Table A2 An illustration of the process of coding from the two data sets inductively

\begin{tabular}{|c|c|c|c|c|}
\hline Final themes & Main themes & $\begin{array}{l}\text { Initial themes } \\
\text { and subthemes }\end{array}$ & Codes & Quotes examples \\
\hline \multirow[t]{14}{*}{$\begin{array}{l}\text { E-cigarettes as } \\
\text { ambiguous } \\
\text { novelty }\end{array}$} & \multirow[t]{5}{*}{$\begin{array}{l}\text { The ambiguity of } \\
\text { electronic cigarettes' } \\
\text { status and efficacy }\end{array}$} & $\begin{array}{l}\text { Theme: status } \\
\text { and efficacy } \\
\text { debate }\end{array}$ & $\begin{array}{l}\text { E-cigarettes as } \\
\text { alternative to } \\
\text { smoking }\end{array}$ & $\begin{array}{l}\text { 'I think at the moment it is seen as an alternative to smoking' (H6, } \\
\text { advisor) }\end{array}$ \\
\hline & & $\begin{array}{l}\text { Subthemes: } \\
\text { recreational }\end{array}$ & Good substitute & $\begin{array}{l}\text { 'I started with nicotine to smoke, weaned myself off nicotine till it's } \\
\text { nothing and now }[\ldots . .] \text { I use it as a hobby' (9I, user) } \\
\text { 'it is certainly a very good substitute' (11K, user) }\end{array}$ \\
\hline & & \multirow[t]{3}{*}{ Medicinal } & $\begin{array}{l}\text { Effective like or } \\
\text { more than NRT }\end{array}$ & $\begin{array}{l}\text { 'They are effective as Nicotine Replacement Therapy' (S2, advisor) } \\
\text { '...the e-cigarettes [are] better than anything they have on the NHS' } \\
\text { (7G, user) }\end{array}$ \\
\hline & & & \multirow{2}{*}{$\begin{array}{l}\text { E-cigarette as } \\
\text { medicine/ } \\
\text { treatment }\end{array}$} & $\begin{array}{l}\text { 'I think a lot of people self-medicate using the e-cigarettes' } \\
\text { (S3, advisor) }\end{array}$ \\
\hline & & & & $\begin{array}{l}\text { 'I would rather view it as a medicine; as an aid to giving up smoking' } \\
\text { (H1, advisor). } \\
\text { 'For me it's a treatment. It's a way to keep me off tobacco' ( } 14 \mathrm{~N} \text {, user) }\end{array}$ \\
\hline & \multirow[t]{9}{*}{$\begin{array}{l}\text { The ambiguity of } \\
\text { electronic cigarettes' risk }\end{array}$} & $\begin{array}{l}\text { Theme: risk } \\
\text { debate }\end{array}$ & \multirow[t]{2}{*}{$\begin{array}{l}\text { Uncertain about } \\
\text { safety }\end{array}$} & $\begin{array}{l}\text { 'we don't know whether they [electronic cigarettes] are } 100 \% \text { safe at } \\
\text { all' (9l, user) }\end{array}$ \\
\hline & & \multirow[t]{5}{*}{$\begin{array}{l}\text { Subthemes: } \\
\text { health and } \\
\text { safety risk }\end{array}$} & & $\begin{array}{l}\text { 'I wish I could tell them with absolute surety what the safety is and I } \\
\text { can't. I wish I can tell them with absolute surety how much nicotine } \\
\text { they are getting from the product and I can't. So I think there are gaps } \\
\text { there that I would like to fill' (H6, advisor) }\end{array}$ \\
\hline & & & $\begin{array}{l}\text { Uncertain long- } \\
\text { term effect }\end{array}$ & $\begin{array}{l}\text { 'There's no long-term studies. That kind of worries' ( } 12 \mathrm{~L} \text {, user) } \\
\text { '... but what are the health risks for people inhaling propylene glycol } \\
\text { over periods of time' (S2, advisor) }\end{array}$ \\
\hline & & & $\begin{array}{l}\text { E-cigarette is } \\
\text { safe }\end{array}$ & $\begin{array}{l}\text { 'I would say it should be allowed, it doesn't do any harm... the } \\
\text { electronic cigarette does nothing actually' (4D, user) }\end{array}$ \\
\hline & & & $\begin{array}{l}\text { Less harmful } \\
\text { than cigarettes }\end{array}$ & $\begin{array}{l}\text { 'Obviously this is less harmful to you and people around you' (10J, } \\
\text { user) }\end{array}$ \\
\hline & & & & $\begin{array}{l}\text { 'I definitely say look if you have e-cigarette, I rather you keep it in your } \\
\text { bag and if you are really stuck and you are socialising and you are } \\
\text { drinking alcohol I rather you use that than the real cigarette, so in a } \\
\text { way that's a harm reduction' (H4, advisor) }\end{array}$ \\
\hline & & \multirow[t]{3}{*}{ Social risk } & Renormalisation & $\begin{array}{l}\text { 'About how it looks. I think generally there has been a huge amount of } \\
\text { work to achieve the stop smoking ban in public places that is: any } \\
\text { transport, any restaurant, any sort of public place, and I think to allow } \\
\text { electronic cigarettes in those places will be a retrograde step' (H5, } \\
\text { advisor) }\end{array}$ \\
\hline & & & $\begin{array}{l}\text { Develop } \\
\text { addiction to } \\
\text { e-cigarettes }\end{array}$ & $\begin{array}{l}\text { 'It started to happen not that often but I know three instances in the } \\
\text { last few weeks when people are presented to us stated that they } \\
\text { already quit cigarette but wanted to come off electronic cigarettes } \\
\text { and that's brand new for us' (S2, advisor) }\end{array}$ \\
\hline & & & $\begin{array}{l}\text { Maintain } \\
\text { addiction to } \\
\text { nicotine }\end{array}$ & $\begin{array}{l}\text { 'I mean there are no health warnings on it, because no one has } \\
\text { discovered any health dis-benefits apart from the fact that it will keep } \\
\text { you addicted to nicotine. And I think most people who smoke }\end{array}$ \\
\hline
\end{tabular}




\begin{tabular}{lll}
\hline Final themes Main themes & $\begin{array}{l}\text { Initial themes Codes } \\
\text { and subthemes }\end{array}$ & Quotes examples
\end{tabular}

electronic cigarettes, I think, know that nicotine is highly addictive' (14N, user)

Stigma/ 'I think the stigma that smokers had has kind of carried on to the

unacceptability electronic cigarette users in the sense that the stigma surrounding the addiction itself' (12L, user)

'Some people who are already strongly anti-smoking probably won't be happy seeing them. But I think the majority will probably accept them' (S4, advisor)

'My children don't like the fact I use them at all but they are proud of me giving up smoking, my husband prefers it' (1A, user)

Not gateway risk 'I don't think there is any evidence at the moment that children are versus gateway starting to use electronic cigarettes, that it is used as a gateway drug. risk But I don't think we have got enough evidence; longitudinal evidence' (H6, advisor)

'I don't know. But I don't see why they can't happen. If you build up a nicotine addiction through vaping, and one day you walk past an airport .and there's no other way of getting your fix than buying a packet of cigarettes, because no one sells - I can well imagine people will try that' $(12 \mathrm{~L}$, user) 